\title{
The strength problems in the operation of drum hoist cages
}

\author{
Stanisław Wolny, Filip Matachowski, Agata Drzewosz \\ AGH University of Science and Technology, Poland
}

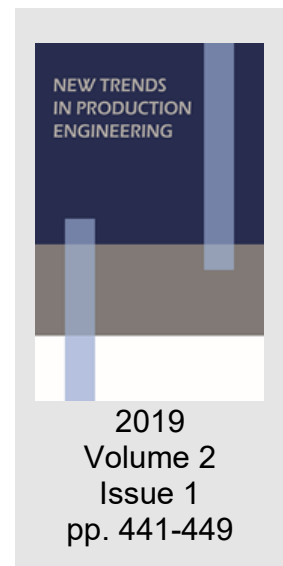

Date of submission to the Editor: 05/2019

Date of acceptance by the Editor: 08/2019

\section{INTRODUCTION}

From information obtained from periodic surveys of cages used in the mine shaft of one of the Polish mines, it appears that the majority of registered damages of their bearing elements are fatigue cracks. These cracks are formed and develop mainly in bearing ties or welds in the areas of their connection with the construction of the cage.

In order to eliminate the causes of these damages and to increase the durability of cages, it will probably be necessary to reconstruct those fragments of the cages in which they occur. For the reconstruction to bring the expected results, it is necessary to know the causes that are the source of the emerging cracks. Therefore, the basic condition from the point of view of strength and fatigue calculations is to determine the loadings of the load-bearing elements of the cage and the state of stress that arises in them. For this purpose, a numerical model of the cage was developed and the appropriate strength calculations were made using the finite element method (FEM).

The results of the calculations made as well as their analysis form the basis for the assessment of the strength and durability of the load-bearing elements of the discussed cage.

The key problem determining the durability of the structure - as shown by the analyzes carried out - is the method of constructing the connection of the tension link with the appropriate elements of the cage. Changing this state requires significant structural changes of these nodes, which the authors of this study pointed out.

\section{ANALYSIS OF OCCURRENCE OF CRACKING ELEMENTS OF CAGES ON THE BASIS OF EXPERT ASSESSMENT OF THE TECHNICAL CONDITION OF THESE CONSTRUCTIONS WORKING IN THE SHAFT IN ONE OF THE POLISH MINES}

The analysis of the occurrence of cracks in the load-bearing elements of the cages was based on expert opinions on the technical condition of these 
structures working in the mine shaft of one of the Polish mines. Tests carried out in the states of these expert opinions included organoleptic tests of the entire structure as well as defectoscopic examination of welds and magnetic-powder testing of tension links. For example, one of the cage devices in Fig. 1 shows the location of the damage found.

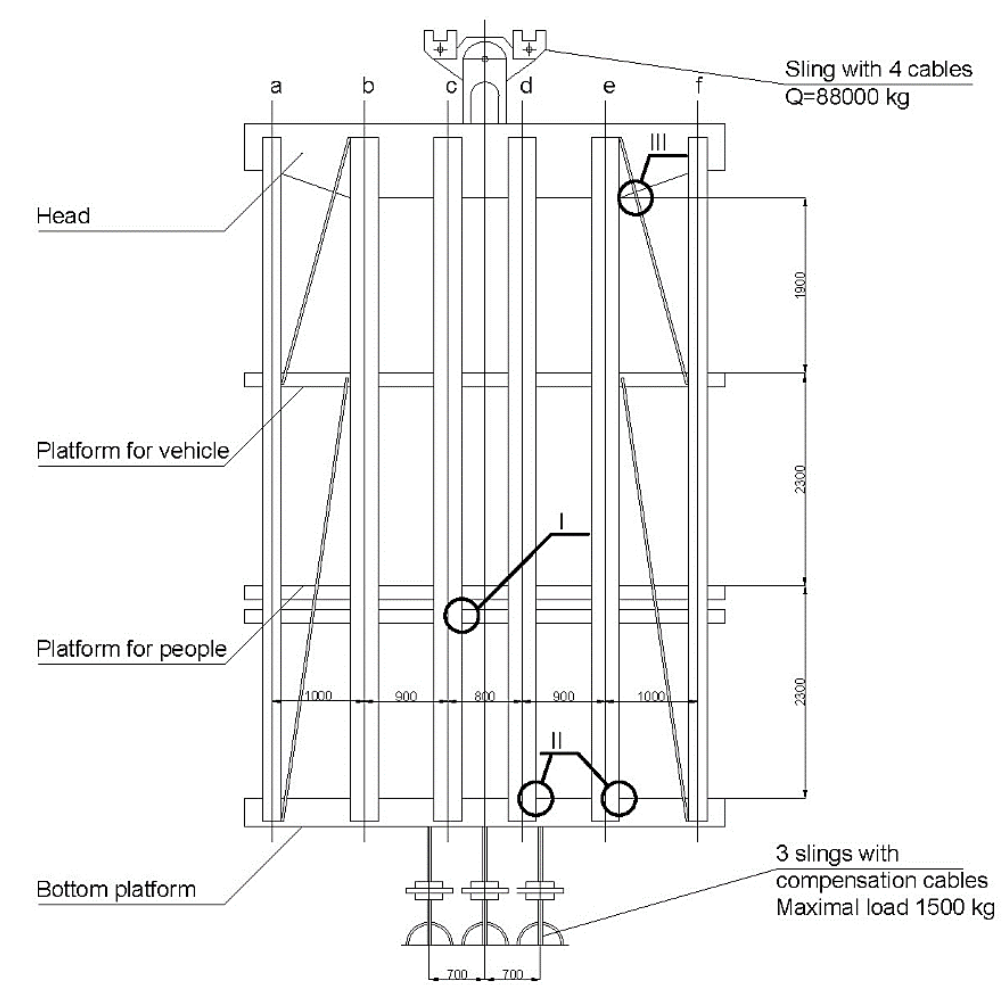

Fig. 1 Locations of damage to load-bearing elements of a cage structure (description in article)

As the first (I) after 47 months of operation, the joints connecting the "c" link (from the right side) with the pull-out platform were found. Next, as a second (II) damage after 69 months of operation, cracks in the joints connecting the "d" and "e" link with the bottom deck were found.

However, after 176 months of construction exploitation, a defect (III) was found, which was the cracking of the weld connecting the "e" support link to the head of the cage. The crack occurred in the lower part of the connection of the tension link with the head, the crack length about $60 \mathrm{~mm}$. During these last tests, the thickness of bearing links of the tested cage was measured. The average measured gauge thickness "a" and "f" was $6.3 \mathrm{~mm}$ and the links "b", "c", "d" and "e" $7.6 \mathrm{~mm}$.

To sum up, in the analyzed cage structure after 70 months of operation, four cracks were observed, in the combination of links with the lower platform two and one fracture in connection of the link with the head and connection of the link in the area of the platform as shown in Fig. 1.

In addition, after 176 months of operation, during testing the thickness of the cage tension links, it was found that, with assumed the same corrosion wear per period of time, the cross-sections of "a" and "f" were reduced by about $10 \%$ and the cross-sections of the middle tension links by about $5 \%$. 


\section{ANALYSIS OF CAUSES OF OCCURRENCE OF CRACKS OF BEARING ELEMENTS OF MINE CAGE CONSTRUCTIONS}

From the information contained in chapter 2 , and obtained from periodic tests of skip and cages operated in shafts of one of the Polish mines, it follows that the majority of registered damage of cage bearing elements is fatigue cracks. These cracks are formed and develop mainly in bearing links or welds, in the areas of their connection with the construction of the cage. In order to eliminate the causes of damage and to increase the durability of the cage construction, it will probably be necessary to reconstruct those parts of the cage in which they occur. For the reconstruction to bring the expected results, it is necessary to learn the causes that are the source of the emerging cracks.

Bearing the above in mind, it was decided to carry out the necessary analyzes that would give knowledge about the loads of links and the state of stress that arises in them in the conditions of normal operation of the system. Therefore, it was decided to carry out appropriate measurements and calculations, which made it possible to determine the load values of bearing elements (links) of the structure, and on this basis to carry out assessments of strength and durability of links and their joints (welds). It should be explained here that the calculation models of load-bearing elements of this type of construction used so far are very simplified and do not fully reflect the resulting stress state caused by transferred loads (Kay, 2010, Thomas, 1988, Journal of Laws). For this purpose, a numerical model was developed for the cage and appropriate strength calculations were made using the finite element method (FEM).

\section{STRENGTH ANALYSIS OF THE CAGE}

Based on the technical documentation of the cage, related to assembly drawing No. M03-2317 (Wolny, 2003), its computational model was developed, which is shown in Fig. 2, on which the numeration of nodes is shown.

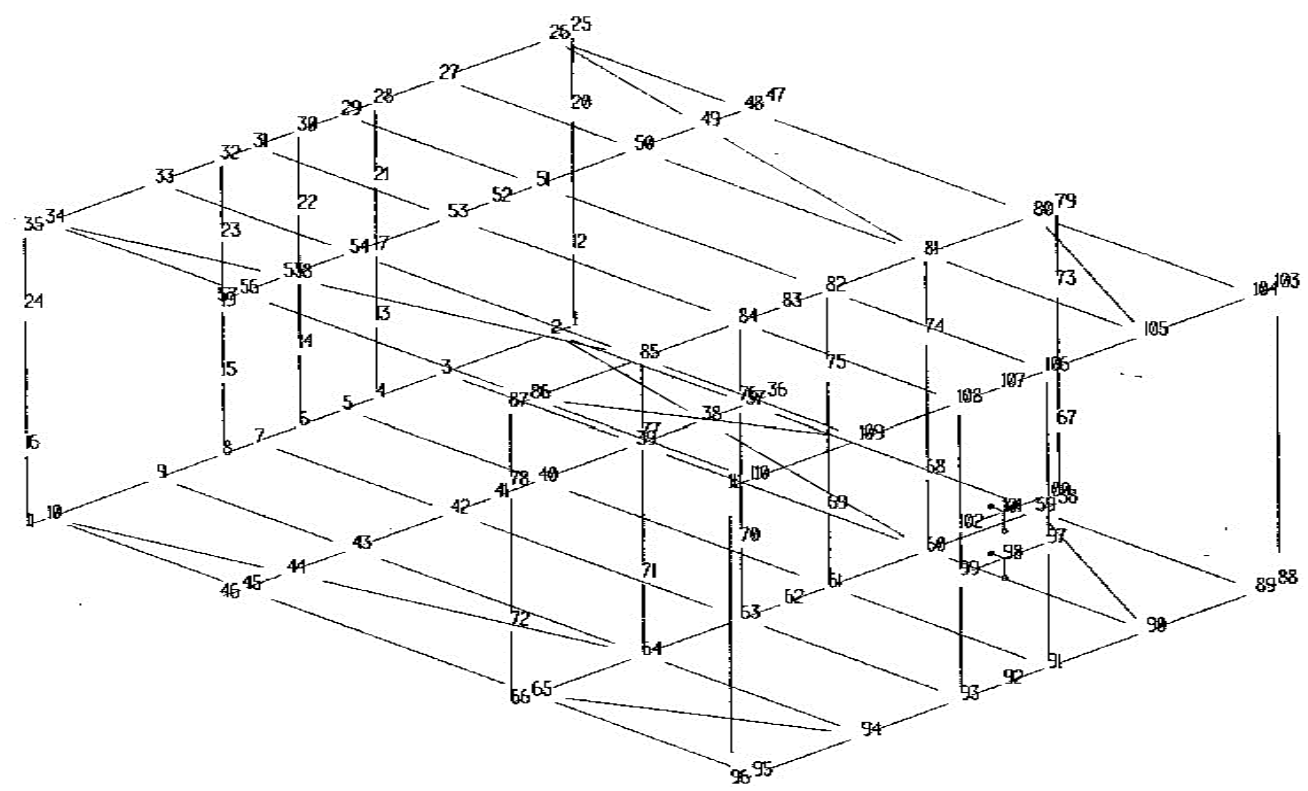

Fig. 2 The calculation model of the frame - numbering of nodes 
In addition, Figure 3 shows the model of the frame with the numbering of the elements.

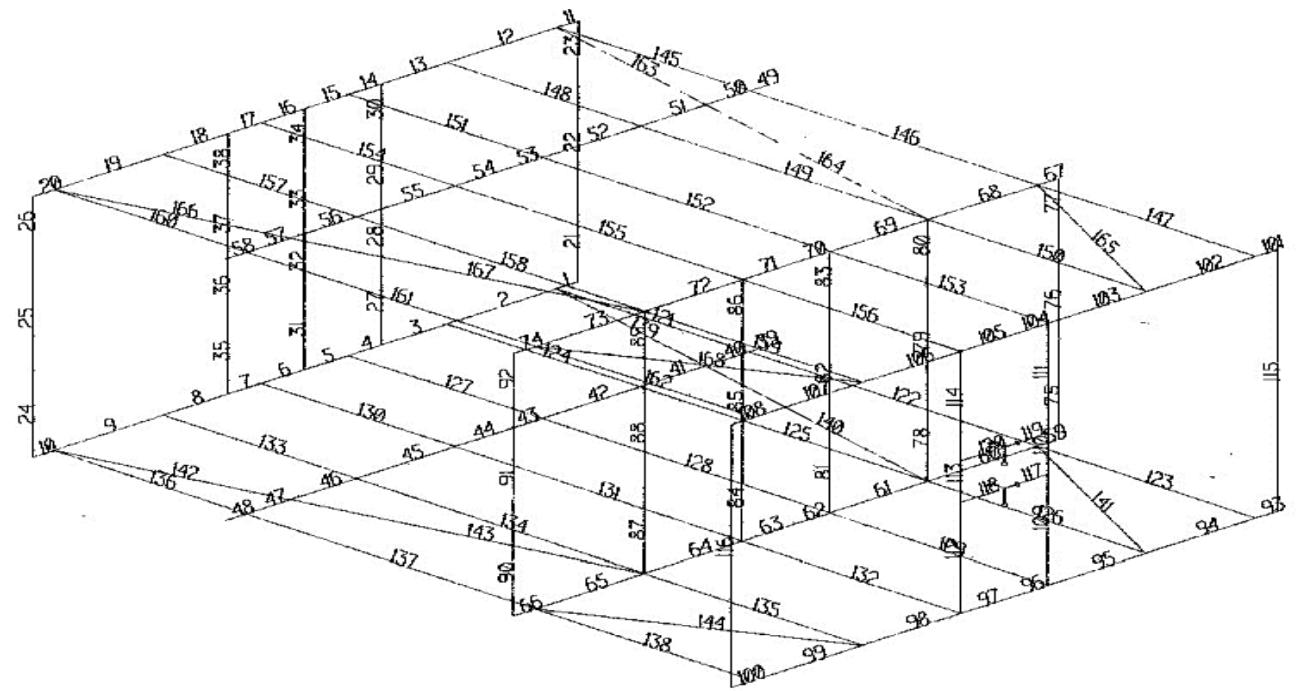

Fig. 3 The calculation model of the frame - numbering of elements

Due to the nature of the work of the cage, people riding or transporting cars with spoil, the load of the model was a combination of the following loads:

- Combinations of loads No. 1 were appropriately distributed:

o own weight of the structure (Figure 4),

o weight of compensating ropes and their suspensions,

o vehicle weight with a load $Q_{w}=12.5 \mathrm{Mg}$ on the lower platform.

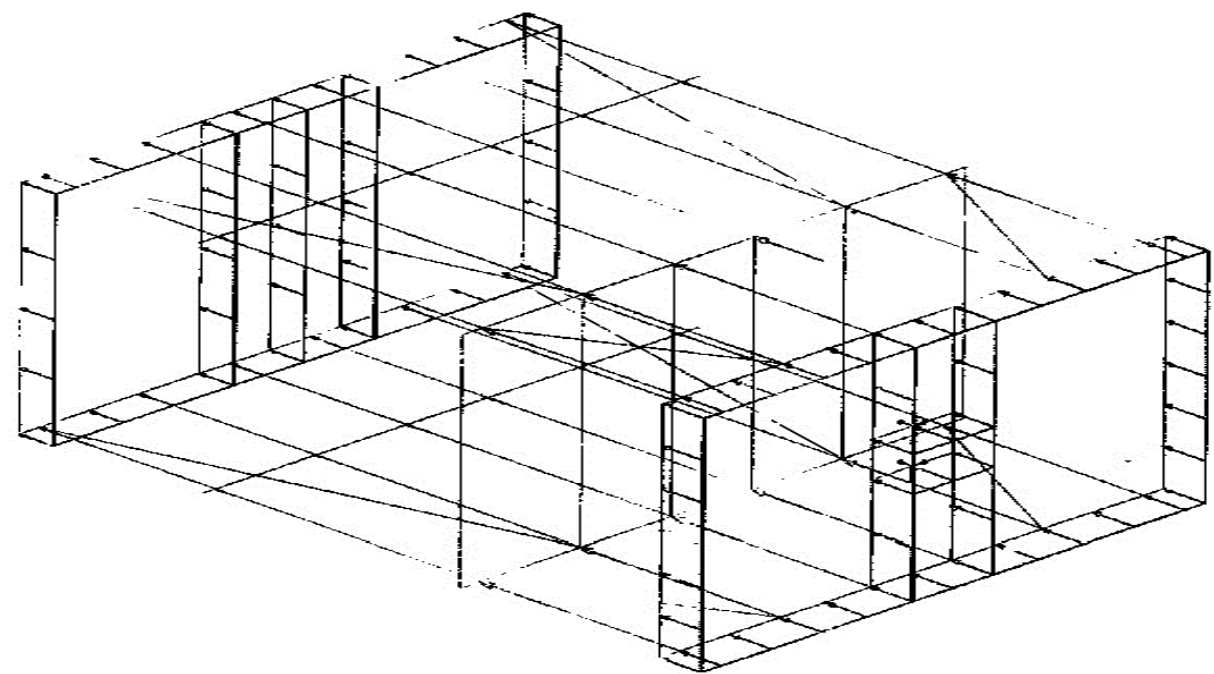

Fig. 4 Loading the cage model with its own weight

- Combinations of loads No. 2 were:

o own weight of the structure,

o weight of compensating ropes and their suspensions,

o loading the platform for carts, the weight of the car along with the spoil,

o loading of the lower platform with the maximum permissible load of the transported load $\mathrm{Q}=20 \mathrm{Mg}$. 
The obtained results of strength calculations were collected and presented in the paper (Wolny, 2003). However, the paper presents the values of stresses in nodes and cross-sections of links that are of most interest to us due to the loadbearing capacity of the structure, i.e. in the places where cracks appear. Only those elements and nodes in which the stresses exceeded $15 \mathrm{MPa}$ and the second combination of loads were selected because higher values of stresses were obtained in all elements and nodes for this load case.

\section{Load - combination No. 2}

Platform footbed elements for human riding - Stresses in any element of this segment (elements 39 to 48 , nodes 36 to 46) of the frame structure did not exceed $5 \mathrm{MPa}$.

The stress values listed in Tables 1-4 show that the stresses of the highest value in the whole model of the cage are formed in its head in elements No. 117 and 118 and amount to $\sigma_{\max }=80 \mathrm{MPa}$. However, in links, stress reaches the maximum value in element No. 129 , for combination No. 2 and is $\sigma_{\max }=28 \mathrm{MPa}$.

Table 1 Elements of the lower frame

\begin{tabular}{|c|c|c|c|c|c|}
\hline Element & Node & $\sigma_{\mathbf{A}}[\mathbf{M P a}]$ & $\sigma_{\mathbf{B}}[\mathbf{M P a}]$ & $\sigma_{\mathbf{C}}[\mathbf{M P a}]$ & $\sigma_{\mathbf{D}}[\mathbf{M P a}]$ \\
\hline 1 & 2 & $-16,57$ & 17,11 & 16,79 & $-16,90$ \\
\hline 2 & 2 & $-14,80$ & 15,38 & 15,42 & $-14,76$ \\
\hline 2 & 3 & $-22,52$ & 23,20 & 23,19 & $-22,54$ \\
\hline 3 & 3 & $-21,78$ & 23,94 & 23,03 & $-22,70$ \\
\hline 4 & 4 & 29,56 & $-30,19$ & $-29,42$ & 30,33 \\
\hline 5 & 4 & 30,08 & $-29,74$ & $-29,55$ & 30,27 \\
\hline 6 & 6 & 34,57 & $-34,37$ & $-34,10$ & 34,84 \\
\hline 7 & 8 & 34,69 & $-34,25$ & $-34,12$ & 34,84 \\
\hline 8 & 8 & 30,11 & $-29,95$ & $-29,66$ & 30,41 \\
\hline 8 & 9 & 29,88 & $-30,10$ & $-29,58$ & 30,40 \\
\hline 9 & 9 & $-22,10$ & 23,52 & 23,06 & $-22,57$ \\
\hline 9 & 10 & $-14,98$ & 15,02 & 15,39 & $-14,61$ \\
\hline 10 & 10 & $-16,67$ & 16,99 & 16,80 & $-16,86$ \\
\hline 21 & 12 & 19,52 & $-19,52$ & $-19,56$ & 19,47 \\
\hline 22 & 12 & 19,52 & $-19,52$ & $-19,56$ & 19,47 \\
\hline 22 & 20 & 19,51 & $-19,52$ & $-19,56$ & 19,47 \\
\hline 23 & 20 & 19,51 & $-19,52$ & $-19,56$ & 19,47 \\
\hline 28 & 17 & 21,88 & $-21,93$ & $-21,90$ & 21,91 \\
\hline 29 & 17 & 21,88 & $-21,93$ & $-21,90$ & 21,91 \\
\hline 32 & 18 & 21,58 & $-21,60$ & $-21,59$ & 21,59 \\
\hline 33 & 18 & 21,58 & $-21,60$ & $-21,59$ & 21,59 \\
\hline
\end{tabular}

Table 2 Platform elements for cars

\begin{tabular}{|c|c|c|c|c|c|}
\hline Element & Węzły & $\boldsymbol{\sigma}_{\mathbf{A}}[\mathbf{M P a}]$ & $\boldsymbol{\sigma}_{\mathbf{B}}[\mathbf{M P a}]$ & $\boldsymbol{\sigma}_{\mathbf{C}}[\mathbf{M P a}]$ & $\boldsymbol{\sigma}_{\mathbf{D}}[\mathbf{M P a}]$ \\
\hline 78 & 68 & 17,06 & $-16,49$ & $-17,03$ & 16,51 \\
\hline 79 & 68 & 17,06 & $-16,49$ & $-17,03$ & 16,51 \\
\hline 79 & 74 & 17,05 & $-16,49$ & $-17,03$ & 16,51 \\
\hline 80 & 74 & 17,05 & $-16,49$ & $-17,03$ & 16,51 \\
\hline 81 & 69 & 17,79 & $-17,86$ & $-17,86$ & 17,79 \\
\hline 82 & 69 & 17,79 & $-17,86$ & $-17,86$ & 17,79 \\
\hline 82 & 75 & 17,79 & $-17,86$ & $-17,86$ & 17,79 \\
\hline 83 & 75 & 17,79 & $-17,86$ & $-17,86$ & 17,79 \\
\hline
\end{tabular}


Table 3 Head elements

\begin{tabular}{|c|c|c|c|c|c|}
\hline Element & Węzły & $\boldsymbol{\sigma}_{\mathbf{A}}[\mathbf{M P a}]$ & $\boldsymbol{\sigma}_{\mathbf{B}}[\mathbf{M P a}]$ & $\boldsymbol{\sigma}_{\mathbf{C}}[\mathbf{M P a}]$ & $\boldsymbol{\sigma}_{\mathbf{D}}[\mathbf{M P a}]$ \\
\hline 95 & 91 & $-15,47$ & 16,10 & 15,24 & $-16,34$ \\
\hline 96 & 91 & $-20,83$ & 20,49 & 20,24 & $-21,09$ \\
\hline 96 & 92 & $-20,80$ & 20,45 & 20,20 & $-21,05$ \\
\hline 97 & 92 & $-20,80$ & 20,45 & 20,20 & $-21,05$ \\
\hline 97 & 93 & $-20,84$ & 20,48 & 20,24 & $-21,09$ \\
\hline 98 & 93 & $-15,47$ & 16,11 & 15,24 & $-16,34$ \\
\hline 109 & 97 & $-24,29$ & 24,28 & 24,37 & $-24,20$ \\
\hline 110 & 97 & $-24,29$ & 24,28 & 24,35 & $-24,22$ \\
\hline 110 & 100 & $-15,11$ & 15,14 & 15,14 & $-15,12$ \\
\hline 111 & 100 & $-15,12$ & 15,14 & 15,16 & $-15,10$ \\
\hline 117 & 97 & 52,12 & $-52,27$ & $-52,16$ & 52,23 \\
\hline 117 & 98 & $-79,77$ & 79,87 & 79,82 & $-79,83$ \\
\hline
\end{tabular}

Table 4 Elements of the side wall

\begin{tabular}{|c|c|c|c|c|c|}
\hline Element & Węzły & $\boldsymbol{\sigma}_{\mathbf{A}}[\mathbf{M P a}]$ & $\boldsymbol{\sigma}_{\mathbf{B}}[\mathbf{M P a}]$ & $\boldsymbol{\sigma}_{\mathbf{C}}[\mathbf{M P a}]$ & $\boldsymbol{\sigma}_{\mathrm{D}}[\mathrm{MPa}]$ \\
\hline 126 & 60 & $-21,82$ & $-14,04$ & $-4,08$ & $-11,86$ \\
\hline 126 & 90 & $-6,79$ & $-18,30$ & $-20,91$ & $-9,39$ \\
\hline 127 & 5 & $-13,68$ & $-23,22$ & $-17,12$ & $-7,58$ \\
\hline 127 & 40 & $-20,43$ & $-11,96$ & $-11,12$ & $-19,59$ \\
\hline 128 & 40 & $-15,39$ & $-17,59$ & $-15,80$ & $-13,61$ \\
\hline 128 & 61 & $-12,11$ & $-12,23$ & $-20,52$ & $-20,40$ \\
\hline 129 & 61 & $-27,52$ & $-22,97$ & $-11,73$ & $-16,27$ \\
\hline 129 & 91 & $-15,94$ & $-22,17$ & $-25,37$ & $-19,14$ \\
\hline
\end{tabular}

\section{Extreme stress values in a model (II combination of loads)}

\begin{tabular}{|l|c|c|c|c|}
\cline { 2 - 5 } \multicolumn{1}{c|}{} & $\boldsymbol{\sigma}_{\mathbf{A}}[\mathrm{MPa}]$ & $\boldsymbol{\sigma}_{\mathrm{B}}[\mathrm{MPa}]$ & $\boldsymbol{\sigma}_{\mathrm{C}}[\mathrm{MPa}]$ & $\boldsymbol{\sigma}_{\mathrm{D}}[\mathrm{MPa}]$ \\
\hline Max global & 52,12 & 79,87 & 79,82 & 52,53 \\
\hline Element & 117 & 117 & 117 & 117 \\
\hline Node & 97 & 98 & 98 & 99 \\
\hline
\end{tabular}

\section{ASSESSMENT OF FATIGUE DURABILITY}

\section{Estimate the number of cycles}

On the basis of the analysis of landings of vehicles and people driving in the shaft in which the analyzed cage works, for a few working days the average number of load cycles was determined, assuming $50 \%$ of working cycles on Saturday and zero cycles on Sunday. The calculated number of operating cycles for 10 and 15 years are listed in Table 6. The calculations do not include maintenance breaks, so the actual number of load cycles may be slightly smaller.

Table 6

\begin{tabular}{|c|c|}
\hline \multicolumn{2}{|c|}{ Number of working cycles } \\
\hline 10 years & 15 years \\
\hline $0.58 \cdot 10^{6}$ & $0.86 \cdot 10^{6}$ \\
\hline
\end{tabular}

Based on the results summarized in Table 6 , for further calculations, $N=1 \cdot 10^{6}$ cycles were assumed as the number of operating cycles after 15 years of operation. 
Eurocode 3 recommends fatigue strength $\Delta \sigma_{R}$ and $\Delta T_{R}$ to determine depending on the expected number of stress cycles $\mathrm{N}$ and the fatigue category of a structure element or connection $\left(\Delta \sigma_{c}\right.$ and $\left.\Delta \sigma_{c}\right)$ according to the following formula:

$$
\Delta \sigma_{R}=0,735 \Delta \sigma_{c}\left(\frac{5 \cdot 10^{6}}{N}\right)^{\frac{1}{m}} \geq \Delta \sigma_{c}
$$

where:

$m=3$ for $N \leq 5 \cdot 10^{6}$

$m=5$ for $N>5 \cdot 10^{6}$

$\Delta \sigma_{c}-$ fatigue category (normative fatigue strength)

$\Delta \sigma_{L}-$ fatigue strength lasted (Eurocode 3).

Design resistance according to Eurocode 3 due to fatigue should be checked according to the formula:

$$
\Delta \sigma_{c} \leq \frac{\Delta \sigma_{\mathrm{R}}}{\gamma_{f a t}}
$$

where:

$\gamma_{f a t}=1 \div 1,2-$ partial fatigue safety factor when material

The value of the coefficient depends on the conditions of operation, inspection and maintenance. For average conditions you can take $\gamma_{f a t}=1$, and for extreme $\gamma_{\text {fat }}=1,2$.

\section{DETERMINATION OF FATIGUE}

The connection of tension links with a platform for cars and a platform for human are made with double-sided fillet welds, thus the most unfavorable fatigue category $\Delta \sigma_{\mathrm{C}}=45 \mathrm{MPa}$.

Thus, fatigue strength according to the dependence (1):

$$
\Delta \sigma_{R}=0,735 \cdot 45 \cdot\left(\frac{5 \cdot 10^{6}}{1 \cdot 10^{6}}\right)^{\frac{1}{3}}=56,56 \mathrm{MPa}
$$

Design resistance according to Eurocode 3 due to fatigue should be checked from formula (2). For the average control and maintenance conditions, $\gamma_{\text {fat }}=$ 1 can be used, hence

$$
\Delta \sigma_{e} \leq \frac{\Delta \sigma_{\mathrm{R}}}{\gamma_{f a t}}=\frac{56,56}{1}=56,56 \mathrm{MPa}
$$

However, the links of the cage structure are connected with the head and the bottom platform with fillet welds (shear) in the direction of the length of the joints, thus according to (Eurocode 3) $\Delta \sigma_{c}=80 \mathrm{MPa}$. Therefore, the tensile strength of the tendon in connection with the head or lower platform according to the dependence (1) is:

$$
\Delta \sigma_{R}=0,735 \cdot 80 \cdot\left(\frac{5 \cdot 10^{6}}{1 \cdot 10^{6}}\right)^{\frac{1}{3}}=100 \mathrm{MPa}
$$


Similarly, as above, the bearing capacity of the structure according to (Eurocode 3 ) due to fatigue should be checked according to the formula (2). For the average control and maintenance conditions, $\gamma_{\text {fat }}=1$ can be used, hence:

$$
\Delta \sigma_{e} \leq \frac{\Delta \sigma_{\mathrm{R}}}{\gamma_{\text {fat }}}=\frac{100}{1}=100 \mathrm{MPa}
$$

Confronting the obtained values of the stress amplitude $\Delta \sigma_{e}=56.56 \mathrm{MPa}$ for connecting the links with the platform for cars as well as for people and $\Delta \sigma_{e}=$ $100 \mathrm{MPa}$ in combination of links with the head and bottom platform, it was found that the cage can be safely operated for 15 years, because $\Delta \sigma<\Delta \sigma_{e}$.

The above calculations were made defining the cycle as a stress change associated with the loading and unloading of the cage, and the amplitude of the stress change was determined based on the maximum stresses determined in a specific element during the device operation $\sigma_{\max }$ and $\sigma_{\min }=0$ in the element without load. W in fact, between the loading and unloading of the cage, there is a whole block of stress change (Wolny, 2003), determined in this case in the exploitation conditions of the extraction vessel (skip). Numerical analysis showed that between the above stress points changed around $6 \cdot 10^{2}$ cycles (Wolny, 2003). W In this case, as the number of cycles for 15 years of construction work of the cage, it should be assumed equal:

$$
N \cong 6 \cdot 10^{2} \cdot 10^{6}=6 \cdot 10^{8}
$$

Therefore, for connecting the links with platforms for human riding as well as for pulling carts

$$
\Delta \sigma_{R}=0.735 \cdot \Delta \sigma_{c} \cdot\left(\frac{5 \cdot 10^{6}}{6 \cdot 10^{8}}\right)^{\frac{1}{5}}=15.96 \mathrm{MPa}
$$

When comparing the obtained value $\Delta \sigma_{R}$ with the values set in Tables 1-4, we note that safe operation for 15 years of the cage is doubtful. This analysis confirms the occurrence of fatigue cracks even after several years of construction exploitation (Wolny, 2003).

\section{CONCLUSION}

The analysis of the fatigue life of the tension links in connection with the construction elements of the cage indicates the possibility of developing fatigue cracks in the most intense areas of the structure in the short term. This thesis is confirmed by the observation of cages exploited in both copper and coal mining (Wolny, 2003).

In the light of the above, it seems necessary to perform a more comprehensive fatigue-strength analysis in the aspect of modernization of the cage construction, especially connections, which would aim to increase fatigue life. Conducting such an analysis may be the basis for the development of criteria for assessing the safe lifetime of the constructions under consideration. 


\title{
REFERENCES
}

Kay, K. (2010). Brake Control Strategy After-Stop Conveyance Oscillation and Haul. International Conference on Hoisting and Haulage. Las Vegas, Nevada, United States.

Thomas, G.R. and Greenway M. E. (1988). Shaft Steel and Conveyance Dynamics. Conference of Hoisting of Men, Materials and Minerals. Toronto.

Dziennik ustaw nr 99. Poz. 1003. Rozporządzenie Rady Ministrów z dnia 30 kwietnia 2004r., „W sprawie dopuszczenia wyrobów do stosowania w zakładach górniczych".

Eurocode 3: Design of steel structures. PN-EN 1993

Wolny, S. (2003). Wybrane problemy wytrzymałościowe w eksploatacji górniczych urządzeń wyciągowych. Monografia. Problemy Inżynierii Mechanicznej i Robotyki. Kraków, AGH.

\begin{abstract}
.
From information obtained from periodic surveys of cages used in the shaft of one of the Polish mines, it appears that the majority of registered damages of their supporting elements are fatigue cracks. These cracks are formed and develop mainly in main nodes or welds in the areas of their connection with the construction of the cage. In order to eliminate the causes of these damages and to increase the durability of cages, it will probably be necessary to reconstruct those fragments of the cages in which they occur. In order to determine loadings of load-bearing elements and the state of stress that arises in them during the operation of the device, a numerical model of the cage was developed. The results of the calculations made as well as their analysis form the basis for the assessment of the strength and durability of the load-bearing elements of the discussed cage. The key problem determining the durability of the structure - as shown by the analyzes carried out - is the method of constructing the connection of the strings with the appropriate elements of the cage. Changing this state requires significant structural changes of these nodes, which the authors of this study pointed out.
\end{abstract}

Keywords: Drum hoist cage, strength analysis, fatigue damage 